\title{
The Effect from CeO2 to W-2 High-temperature Enamel Coating's Microstructure and Coefficient of Thermal Expansion
}

\author{
Cheng Wang ${ }^{1, a}$, Congyan Zhang ${ }^{2, b}$, Xiaojun Shen ${ }^{1, c^{*}}$, and Yan Chai ${ }^{1, d}$ \\ ${ }^{1}$ Science and Technology on Plasma Dynamics Laboratory, Air Force Engineering University, Xi'an, \\ Shanxi, 710038, China \\ ${ }^{2}$ The 5713 Plant of PLA, Xiangyan, Hubei, 41000, China \\ aemailwarrant_74@126.com, ${ }^{b}$ zcy5713@163.com, ${ }^{c^{*}}$ s673864902@126.com, \\ dchaiyan1026@126.com
}

Keywords: $\mathrm{CeO} 2$; enamel coasting; thermal expansion.

Abstract. The W-2 high-temperature enamel coating which coated on the surface of the K403 guide vane, presents the faults of coating's collapsing and cracking frequently in use because of the greater difference between W-2 high-temperature enamel coating and K403 alloy in coefficient of thermal expansion. In order to solve the problem, this study adds $\mathrm{CeO} 2$ into the $\mathrm{W}-2$ high-temperature enamel frit and tests the microstructure and coefficient of thermal expansion with or without $\mathrm{CeO} 2$. Test results show that the coating's microstructure becomes more evenly, the surface becomes more smooth, and the coefficient of thermal expansion is improved

\section{Introduction}

High-temperature enamel coating is a glass or ceramic coating to resist oxidation and corrosion, isolate electric and do other protections for base metal, which is coated on the surface of metal parts by high-temperature fusion sintering technology ${ }^{[1]}$. For enamel coating is an excellent coating material of metal surface, it has a good anti-oxidation, good anti-corrosion, high hardness, low price and other characteristics, and it makes its expansion coefficient closed to the base metal by adjusting its composition ${ }^{2 \sim 6]}$. The cast Ni-base superalloy K403 with a better oxidation resistance and an excellent endurance property and a good fatigue property is mainly used for the guide vane of aero-engine ${ }^{[7]}$. There will coat a layer of W-2 high-temperature enamel coating on its surface for protecting, but this coating is always collapsed or cracked in practice. After analyzing, the cause of this problem is the greater difference between the coating's and the base metal's coefficient of liner expansion. For solving this problem, $\mathrm{CeO} 2$ is added into enamel glaze to improve the enamel's coefficient of thermal expansion and interfacial bonding strength in the paper. This paper mainly does the study on W-2 high-temperature enamel coating's microstructure and coefficient of thermal expansion after adding CeO2.).

\section{Experimentation}

Experimental Material. The base material is the cast Ni-base superalloy K403, and its major chemical components is showed in Table 1. The base material superalloy K403 is cut into cylindrical samples of $\varphi 10 \mathrm{~mm} \times 5 \mathrm{~mm}$ by wire cutting. Firstly the surface of samples will be polished by No.600 metallographic sandpaper, then do uniform sandblasting on samples by emery to reach the samples' surface roughening to $\mathrm{Ra}=0.2 \mathrm{~mm}$, and use the ultrasonic wave of propel alcohol solution to degrease and clean by $10 \mathrm{mins}$ for spare.

Table 1 Superalloy K403's major chemical components(\%)

\begin{tabular}{ccccccccc}
\hline $\mathrm{C}$ & $\mathrm{Cr}$ & $\mathrm{Co}$ & $\mathrm{W}$ & $\mathrm{Mo}$ & $\mathrm{Al}$ & $\mathrm{Ti}$ & $\mathrm{Fe}$ & $\mathrm{Ni}$ \\
\hline $0.11 \sim 0.18$ & $10.0 \sim 12.0$ & $4.5 \sim 6.0$ & $4.8 \sim 5.5$ & $3.8 \sim 4.5$ & $5.3 \sim 5.9$ & $2.3 \sim 2.9$ & 2.0 & allowance \\
\hline
\end{tabular}


Enamel Coating Preparation. According to the references ${ }^{[1]}$, the chemical components of W-2 high-temperature enamel coating and W-2 enamel glaze can be respectively showed in Table 2 and Table 3, and the coefficient of thermal expansion of W-2 high-temperature enamel coating is showed in Table 4.

Table 2 The chemical components of frit in W-2 high-temperature enamel coating

\begin{tabular}{ccccccc}
$\begin{array}{c}\text { Chemical } \\
\text { components }\end{array}$ & $\mathrm{SiO}_{2}$ & $\mathrm{BaO}$ & $\mathrm{CaO}$ & $\mathrm{ZnO}$ & $\mathrm{BeO}$ & $\mathrm{MoO}_{3}$ \\
\hline Mass fraction(\%) & 43.0 & 42.5 & 4.0 & 5.0 & 2.5 & 3.0 \\
\hline \multicolumn{4}{c}{ Table 3 The chemical components and phr of W-2 enamel glaze } \\
\hline $\begin{array}{c}\text { Chemical } \\
\text { components }\end{array}$ & $\begin{array}{c}\text { Raw material } \\
\text { of enamel }\end{array}$ & $\mathrm{Cr}_{2} \mathrm{O}_{3}$ & Clay & Water \\
\hline phr & 70 & 30 & 5 & 70
\end{tabular}

Table 4 the liner expansion coefficient of W-2 high-temperature enamel coating

\begin{tabular}{cccccc}
\hline Temperature $/{ }^{\circ} \mathrm{C}$ & $20 \sim 100$ & $20 \sim 100$ & $20 \sim 100$ & $20 \sim 100$ & $20 \sim 100$ \\
\hline $\begin{array}{c}\text { Liner expansion } \\
\text { coefficient }\end{array}$ & 5.61 & 6.41 & 6.70 & 6.85 & 6.94 \\
$/\left(10^{-6-1}\right)$ & & & & & \\
\hline
\end{tabular}

All kinds of powers are added into jar mill to the proportion requirements in Table 2 and Table 3 , so does $\mathrm{CeO} 2$ with the dosage of $2.0 \% \sim 3.0 \%$. And then the W-2 high-temperature enamel glaze will be got after 10 hours' ball-milling by planetary ball mill of Type QMSB.

Using compressed air spraying with air pressure of $1.0 \mathrm{MPa}$, we coat a W-2 high-temperature enamel coating on the surface of superalloy K403 about 40 60um.

Put glaze into the Ni mould with a $3 \times 4 \times 25 \mathrm{~mm}$ inner cavity, then after drying put it into the muffle furnace with $1190^{\circ} \mathrm{C}$ for 20 minutes, then get the W-2 enamel coating sample by air cooling to room temperature.

Test Method. Observe the enamel coating sample's surface and cross-section topography by the Type Laica Stereo Scan-440 SEM ( backscatter electron image), analyze the 3D topography of the enamel coating's surface by the Type NanoScope-IV AFM, and test the thermal expansion coefficient of the sample by Type DIL402PC thermal dilatometer.

\section{Experimental Results and Analysis}

The Effect from CeO2 to W-2 High-temperature Enamel Coating's Microstructure. As Fig.1 showed with the SEM image is the cross-section topography of the W-2 enamel coating sintered on the superalloy $\mathrm{K} 403$ whether the $\mathrm{CeO} 2$ is added. This proves, the $\mathrm{W}-2$ enamel coating without $\mathrm{CeO} 2$ contains a certain number of pores under the sintering technology. The reason is that the ceramic glaze's higher viscosity stops the pores leaving from the coating and the pores leaving behind makes the defect of intra-coating. As the number of pores in W-2 enamel coating with $\mathrm{CeO} 2$ is significantly reducing, $\mathrm{CeO} 2$ makes the suspension liquid's viscosity lower and improves its liquidity to make the pores overflow easier 


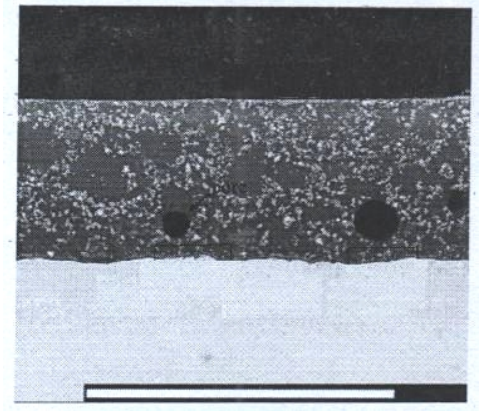

(a)Ordinary

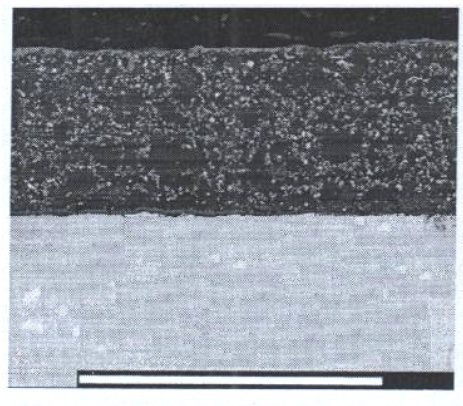

(b) $\mathrm{CeO}_{2}$ addition

Fig. 1 SEM image of the W-2 enamel coating's cross-section topography

As Fig. 2 showed with the AFM image is 2 kinds of the 3D topography of enamel coating's surface. Combined with Fig.1 and Fig.2.we find out the microstructure of enamel coating with $\mathrm{CeO} 2$ has a better compactness and smaller oxide particles and refined grains for the high antioxidant property of $\mathrm{CeO} 2$. Ce has 2 valence states in enamel coating as $\mathrm{Ce} 2+$ and $\mathrm{Ce} 4+$. As $\mathrm{Ce} 4+$ has light and thermal sensing properties, it easily accepts valence electron in the sintering process of enamel coating and changes the energy in ceramic glaze to trigger the spontaneous nucleation which then lead to lower the crystallization activation energy and refine grains and compact the microstructure.

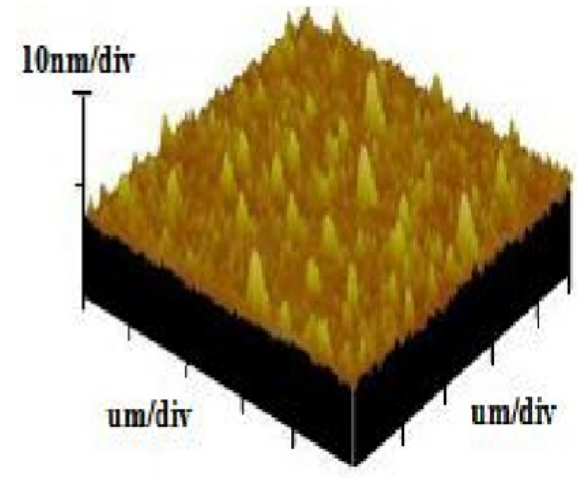

(a)Ordinary

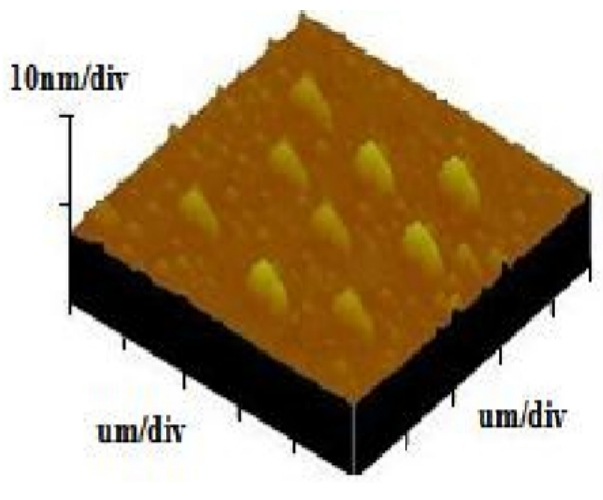

(b) $\mathrm{CeO}_{2}$ addition

Fig. 2 AFM image of the surface of enamel coatings

The Effect from CeO2 to W-2 High-temperature Enamel Coating's Coefficient of Thermal Expansion .The thermal expansion of coefficient of the coating has a important effect on the adhesive force of it. This is, as if the coating and base metal's thermal expansion coefficient has a great difference, their deformation and stress accompanying is quite different and will lower the adhesive force and even worse make the coating fall off the base metal with two material's different expansion values when surrounding temperature changes. As the high-temperature coating applied in aero-engine, the safety of W-2 high-temperature enamel coating will be heavily affected by the big change in temperature during using. So, the matching to the base metal's thermal expansion coefficient must be considered when design the coating.

Test the sample's thermal expansion coefficient under $20 \sim 100^{\circ} \mathrm{C} 、 20 \sim 200^{\circ} \mathrm{C} 、 20 \sim 300^{\circ} \mathrm{C} 、 20 \sim 400^{\circ} \mathrm{C}$ and $20 \sim 500^{\circ} \mathrm{C}$ by Type DIL402PC thermal dilatometer. The results is showed in Table 5.

Table 5 The liner expansion coefficient of W-2 high-temperature enamel coating

\begin{tabular}{ccccc} 
Temperature $\left({ }^{\circ} \mathrm{C}\right)$ & $20 \sim 100$ & $20 \sim 200$ & $20 \sim 300$ & $20 \sim 400$ \\
\hline $\begin{array}{c}\text { Liner expansion } \\
\text { coefficient }\left(10^{-6} /{ }^{\circ} \mathrm{C}\right)\end{array}$ & 6.61 & 7.41 & 7.70 & 7.85 \\
\hline
\end{tabular}


From Table 5 and Table 4, after added $\mathrm{CeO} 2$, the thermal expansion coefficient of W-2 high-temperature enamel coating has a better improvement than before. The liner expansion coefficient of $20 \sim 100^{\circ} \mathrm{C}$ is improved $17.8 \%, 20 \sim 500^{\circ} \mathrm{C}$ is improved $14.4 \%$, which improving the difference between W-2 high-temperature enamel coating and superalloy K403's thermal expansion coefficient.

\section{Conclusion}

$\mathrm{CeO} 2$ can improve the microstructure and morphology in the enamel coating. The distribution of its hard phase is scattered, and hard grains is well combined with surrounding coating. The enamel coating's grains are refined and the microstructure is compacted and the toughness is improved, therefore, to improve the thermal expansion coefficient of the coating.

\section{Acknowledgments}

The authors are grateful for the support provided by the Science and Development Foundation of Shan xi Province of China(Nos.2014K08-31)

\section{References}

[1]China Aeronautical Materials Handbook Volume 9.(Coating, Coating Layer and Rust-resisting Material) [M].Beijing: Standards Press of China, 2002: 301-306

[2]Guan C H, Tang Z L, Wang F H, et al . Effect of Enamel Coating on Oxidation and Hot Corrosion Resistance of Ti24A114Nb3V [J] . Chinese Journal of Materials Research ,2000, 14 (S1) : 75-80

[3]Finke M, Hughes J A, Parker D M, et al. Mechanical Properties of Insitu Demineralised Human Enamel Measured by 456-467

[4]Zhou M, Li K, Shu D, et al . Corrosion Resistance Properties of Enamels with High B2O3-P2O5 Content to Molten Aluminum[J]. Materials Science and Engineering A, 2003, 346 (1-2) :116-121

[5]Conde A, Damborenea J J de. Electrochemical Impedances Pectroscopy for Studying the Degradation of Enamel Coatings[J] . Corrosion Science, 2002, 44 ( 7) : 1 555-1 567

[6]Wang F H, Tang Z L, Guan C H, et al. A High-temperature Protection Technology for Ti Alloy and Ti-Al Intermetallic Compound [P] . No. 98114349, 1998, 8

[7]GUO Jianting. Materials Science and Engineering for Superalloys( $\square)[\mathrm{M}]$. Beijing: Science Press, 2010, 111 114 